\title{
As Ocupações Supostamente Subalternas: 0 exemplo da enfermagem brasileira
}

\section{The Supposedly Subaltern Professions: the example of Brazilian nursing}

Luiz Antonio de Castro Santos

Sociólogo, PhD em Sociologia pela Universidade de Harvard. Professor Adjunto do Instituto de Medicina Social da UERJ.

Endereço: Rua São Francisco Xavier, 524, BI. E, 7 andar, CEP 20550ol3, Rio de Janeiro, RJ, Brasil.

E-mail: lacsळims.uerj.br

\section{Lina Faria}

Historiadora, Doutora em Saúde Coletiva pelaUERJ, com Pós-doutorado em Política Científica e Tecnológica pela Unicamp/Fapesp. Pesquisadora Associada ao Projeto Nacionalismo e Internacionalismo em Saúde IMS/UERJ.

Endereço: Rua São Francisco Xavier, 524, BI. E, 7. andar, CEP 20550ol3, Rio de Janeiro, RJ, Brasil.

E-mail: linafaria@ims.uerj.br

\section{Resumo}

Este é um estudo sobre a história da formação de Educadoras Sanitárias e Enfermeiras de Saúde Pública na primeira metade do século 20, com destaque para acontecimentos em São Paulo e no Rio de Janeiro. A sociologia histórica proporciona um instrumental teóricometodológico fundamental para análise e interpretação das relações entre instituições, poder e identidades profissionais e, nesse sentido, permite o estudo do processo de demarcação de um território de decisões e de atuação feminina que não fosse marcado pela subalternidade à profissão médica. 0 presente estudo se apóia na literatura histórico-sociológica que discute o movimento de configuração do campo da saúde pública iniciado nos anos de 1920 e estreitamente ligado aos debates sobre a nacionalidade e a constituição de identidades profissionais no campo do Cuidar. A década de 1920 instaurou novas práticas e concepções na relação entre Estado e sociedade, acentuando-se a especialização em saúde pública ou higiene. A formação de novas categorias seguiu um modelo de profissionalização baseado na "feminização" da atenção ao paciente e às famílias. 0 texto discute a formação das profissionais e a organização do campo do trabalho. Conclui-se que a ênfase nas conquistas do poder médico pela literatura tem relegado, a segundo plano, o surgimento do novo campo profissional para jovens mulheres das classes médias e de alguns segmentos urbanos das camadas populares, que passaram a atuar como visitadoras da Educação Sanitária e da Enfermagem de Saúde Pública, bem como nos centros e postos de saúde que se difundiram por várias regiões do país.

Palavras-chave: Sociologia das Profissões; Identidade Profissional; Gênero, Enfermeira de Saúde Pública. 


\section{Abstract}

This is a study about women as health educators and public health nurses in the first half of the $20^{\text {th }}$ century in Brazil. Historical sociology, as a methodological and theoretical tool, will guide our analysis of the relations among institutions, professional power, and identities, highlighting the ways through which women professionals were capable of creating their own territory of autonomous action. In Brazil, the configuration of the public health field in the early 1920 s was intimately associated with nation-building processes, and demanded new professionals for traditionally female occupations. The training of the young candidates took place at the Oswaldo Cruz Institute, in Rio de Janeiro, at São Paulo's Institute of Hygiene, at Medical Schools, in foreign centers such as the Teachers College and the Toronto School of Nursing, as well as by means of on-the-job training. The sociological literature has stressed the (basically male) medical dominance, to the detriment of a focus on the new emerging professions. This trend has been clear in Brazil, and it is time that the "sociological gaze" took a close interest in the unique role played by women as health educators and visiting nurses, based in community health centers as early as 1925 in São Paulo, Rio de Janeiro and other centers, and in rural health units across the nation. Health education was the key element in this new scenario of campaigns against endemic diseases - a national practice which Brazilians called "campanhismo" - that stressed non-authoritarian means in place of old schemes of medical policy. Keywords: Sociology of Professions; Professional Identity; Gender; Public Health Nursing; Health Educators.
“É para fora de nós que devemos olhar, é a história que devemos observar, é toda uma ciência que é preciso instituir, ciência complexa, que só pode avançar lentamente, por um trabalho coletivo"

(Émile Durkheim, 2003 [1912]).

"E o fruto do trabalho é mais que sagrado".

(Beto Guedes e Ronaldo Bastos)

Este texto aborda um capítulo da institucionalização da ciência aplicada no Brasil, à luz da interpretação histórico-sociológica. A formação profissional no Brasil, particularmente a diplomação de educadoras e enfermeiras de saúde pública nas primeiras décadas do século passado, é um campo fecundo para professores, pesquisadores e alunos interessados na Sociologia e História das Profissões em Saúde, das Políticas Públicas e da Cooperação Internacional. Estes campos demandam diferentes recortes analíticos e uso das mais variadas fontes documentais. Trata-se de campos ainda pouco explorados, mas com grandes possibilidades, diante dos inúmeros laboratórios, oficinas e núcleos de pesquisa histórica criados nos últimos anos e difundidos nacionalmente, a partir de São Paulo e do Rio de Janeiro. No entanto, do ponto de vista historiográfico e sociológico, são esforços ainda incipientes (como os nossos), pois até o momento o tema da Enfermagem ocupa ainda um espaço de "segunda classe" na literatura sociológica e na historiografia nacional, diferentemente do que se passa no exterior, onde o tema tem lugar de destaque há várias décadas ${ }^{1}$.

A história da formação de Educadoras Sanitárias paulistas ("normalistas" com treinamento em saúde pública no Serviço Sanitário de São Paulo, desde a década de 1920) e de Enfermeiras de Saúde Pública paulistas e fluminenses (profissionais diplomadas) é um desafio para o estudo de identidades profissionais, pois estas profissões emergentes demarcam um território de decisões e de ação que não constitui simples “poder delegável ou delegado" pela profissão médica. O que se passava em São Paulo e na antiga Capital Federal acarretava efeitos importantes para outras regiões do país, a exemplo dos Estados do Rio Grande do Sul, Pernambuco e Minas Gerais. À medida que o movimento de configuração do "campo sanitário" buscava instaurar novas práticas e concepções, exigia, ao

1 A literatura é vasta, mas dois textos exemplares são Buhler-Wilkerson, 1983 e Fox e col., 1991. 
mesmo tempo, o concurso de novos agentes, acentuando-se a especialização em saúde pública ou higiene. A formação dessas novas profissionais brasileiras e a difusão da educação sanitária eram feitas nos cursos de higiene e saúde pública oferecidos pelo Instituto Oswaldo Cruz e pela Escola Anna Nery no Distrito Federal, pelo Instituto de Higiene de São Paulo (mais tarde, Faculdade de Saúde Pública da USP), pela Faculdade de Medicina da USP, pela formação no exterior e também por treinamento em serviços ou departamentos estaduais e federais.

O presente trabalho procura sublinhar o processo de profissionalização da mulher brasileira no campo da saúde, ao longo da Primeira República². Atentos a descobrir a face de subordinação hierárquica ao poder médico, procuramos apontar a ampliação considerável de espaços de autonomia, ou de "graus de liberdade" de atuação, seja no interior dos hospitais ou no trabalho de visitação às famílias ou comunidades. 0 associativismo, a produção científica em periódico de circulação nacional, bem como a realização de congressos, no caso da Enfermagem, foram, desde cedo, nas décadas de 1920 e no início da "Era Vargas", elementos importantes para defender e configurar um espaço profissional autônomo. Por outro lado, não somente no interior da Enfermagem, mas também entre as Educadoras Sanitárias - e, em nossos dias, de maneira renovada, entre as equipes do Programa de Saúde da Família -, a educação para a saúde firmou-se como um objetivo fundamental de ligas de saneamento, no passado, e de movimentos sociais, no presente, como instrumentos de pressão para a formulação de políti- cas estatais (Castro Santos e Faria, 2005). Referimonos aos elementos comuns das atividades e serviços, hoje como naqueles tempos pioneiros, da prevenção de doenças contagiosas e parasitárias; da promoção da saúde comunitária; do pré-natal à educação nutricional e à redução da mortalidade infantil. ${ }^{3}$

0 trabalho traz à tona questões atuais de construção de identidade profissional nas profissões de saúde $^{4}$ : as educadoras sanitárias de então, por serem profissionais de formação considerada "incompleta" por suas colegas enfermeiras (estas, aptas não somente para o trabalho das visitadoras, mas igualmente para o trabalho hospitalar), podem ser comparadas, à guisa de ilustração, às Agentes Comunitárias de Saúde (inicialmente uma atividade feminina) nos tempos atuais. As questões de conflito de autoridade no interior da própria atividade do Cuidar afloravam entre Enfermeiras e Educadoras Sanitárias, no passado, e parecem emergir entre Enfermeiros e Agentes Comunitários nos dias de hoje ${ }^{5}$. Esse ponto permite um exame sob diversos ângulos. Uma das possibilidades de análise remete às teias de relacionamento social entre grupos profissionais, oscilando entre níveis de hostilidade ou de afinidade, de rejeição ou de atração. Nesse aspecto, é um procedimento legítimo confrontar os dois pares de profissionais sem recorrer à análise dos diferentes contextos históricos em que se situavam. É perfeitamente legítimo “congelar-se”, fenomenologicamente, a dinâmica interprofissional como num sociograma. Mas um convite à reflexão poderá por certo incorporar os atributos de classe social aos conflitos de autoridade, sugeridos anteriormente. 0 quadro

2 Para o leitor interessado em aprofundar o estudo das transformações da saúde pública nesse período republicano - um processo de modo algum linear, mas tortuoso e carregado de contradições - nosso livro recente (Faria, 2007), discute a saúde como política institucional e campo de conflitos e alianças sociais durante a Primeira República. o texto apresenta, ainda, uma discussão das principais obras voltadas para o tema na literatura nacional. Esses estudos, por certo, não representam vozes uníssonas em relação à interpretação dos processos e marcos institucionais do período, o que indica a complexidade do tema e a dificuldade de conclusões factuais, ao feitio das ciências biomédicas.

3 Desde logo, não se defende aqui que sejam os mesmos os modelos adotados no passado e em nossos dias. Procuramos apenas apontar traços comuns ou comparáveis, em experiências tão distantes no tempo. Para uma discussão dos rumos atuais e objetivos do Programa de Saúde da Família, consulte-se Universidade Federal de Juiz de Fora (2003).

4 Sobre o tema da identidade profissional, durante o período de consolidação da Enfermagem no Brasil, consulte-se Kakehashi (1999). Em exaustivo trabalho de pesquisa nos Annaes de Enfermagem, publicação da Associação Nacional de Enfermeiras Diplomadas (mais tarde, ABEn), a autora discute a "política de identidade profissional desenvolvida pela Associação, no período 1932 a 1941", baseando-se no conteúdo doutrinário e programático daquela publicação oficial.

5 Desde logo, o objetivo da comparação com a atividade recente de agentes comunitários de saúde é tão somente heurístico, não conclusivo. A discussão histórica deve, sempre que possível, levantar pistas para esclarecer fenômenos contemporâneos, em suas diferenças e semelhanças mais significativas. Sobre o Programa dos Agentes Comunitários, consulte-se publicação do Ministério da Saúde (Brasil, 2001). Sobre o PACS e uma das experiências regionais coroada, até recentemente, de relativo êxito, consulte-se Castro Santos (2003). 
paulista das décadas de 1920 a 1940 é, nesse sentido, um convite à análise social: ainda que as educadoras não fossem subordinadas funcionalmente às enfermeiras - como ocorre, hoje, com os agentes comunitários em relação à Enfermagem -, cresceu entre os dois grupos, em São Paulo, uma relação não raro conflituosa, que envolvia questões de hierarquia profissional e competência técnica (Faria, 2006, p. 198-199) ${ }^{6}$. É tentador lembrarmos que, apesar de a origem de classe das educadoras quase sempre colocá-las em situação "superior" - lembremos que as educadoras, por serem normalistas, tinham um perfil de classe média -, as enfermeiras das primeiras turmas formadas pelo Serviço de Enfermagem de Saúde Pública da Faculdade de Higiene e Saúde Pública da USP logo assumiram um papel de liderança. Note-se que, apesar de os atributos de classe "favorecerem" as educadoras na luta pela distinção, foram as Enfermeiras, recrutadas mais democraticamente, que se destacaram em relação àquelas. Hoje, a trama desigual no território da Saúde da Família parece ganhar um sentido ainda mais problemático, do ponto de vista da política institucional. No passado, foi no terreno cognitivo e estratégico, não no campo dos atributos de classe social, que a Enfermagem logrou acumular recursos de auto-organização e alcançar maior poder social do que as Educadoras; todavia, nos dias atuais, a origem de classe desfavorável dos Agentes Comunitários soma-se ao desnível da formação acadêmica e às dificuldades de construir alianças estratégicas, em contraste com o que se dá no âmbito da Enfermagem. Vemos, aqui, como as comparações podem favorecer a reflexão sobre a competição e as possibilidades ou dificuldades de solidariedade grupal, no interior das profissões de saúde.

No passado, foi sobretudo nos centros de saúde que se desenrolou a trama das relações de "aproximação" e "rejeição" entre os grupos profissionais. 0 mesmo se dá nos dias atuais, no interior das equipes de Saúde da Família. Os centros e postos de saúde possibilitavam a proximidade dos novos profissionais da saúde - fossem educadoras ou enfermeiras - com a população rural e urbana ameaçada por endemias e epidemias, como a ancilostomíase, nas áreas rurais, e a febre amarela, nas áreas urbanas. Nosso duplo interesse, pela educadora visitadora e pela enfermeira de saúde pública, se estende aos dois cenários - ao Centro de Saúde e ao trabalho de campo. Note-se que foi a demanda por enfermeiras, para as campanhas sanitárias, que teve um efeito paradoxal: o tempo considerável para diplomar as enfermeiras acabou por gerar a solução mais rápida de um Curso de Educação Sanitária, teórico e prático, que formava as visitadoras em um ano e seis meses. A substituição das visitadoraseducadoras pelas enfermeiras foi gradativa, iniciando-se ainda no final da década de 1940, como resultado da própria superioridade de organização e dos vínculos institucionais mantidos pelas enfermeiras. As atividades, que envolveram os dois perfis de visitadoras, tiveram um efeito multiplicador, pois por força da atuação das profissionais, os centros de saúde e postos de higiene institucionalizaram-se como espaço da atenção à saúde publica. Ainda que, em princípio, houvesse número igual de médicos e visitadoras, a falta de visitadoras em um centro ou posto de saúde implicava na denominação oficial de "subposto". Se na realidade a presença numérica dos médicos era menor, ou o tempo de dedicação mais reduzido ${ }^{7}$, esse fator criava condições ainda mais favoráveis para que as visitadoras interagissem. Isso sem a supervisão dos médicos, pois que a atividade domiciliar cabia a elas, era seu "território". Se a natureza do trabalho era diversa, era não obstante e precisamente neste aspecto, da incumbência das visitas domiciliares, que se descortinava um espaço de atuação independente para aquelas profissionais, nas ações de saúde pública. 0 cenário profissional se diversificava e criava oportunidades crescentes, não somente para tornar mais complexo o jogo de forças, mas também para atenuar as posições hierárquicas rígidas que os atos do cuidar e curar geravam, naquela época (Faria, 2007). Uma última observação: sociologicamente, não basta atentarmos para a conformação da força de trabalho do ponto de vista do predomínio numérico, ou da simetria, na relação entre os sexos. É preciso que superemos o recorte quantitativo e vislumbremos a distribuição de poder entre os profissionais. Sob esse ângu-

\footnotetext{
6 Nesse aspecto, o depoimento da Educadora Sanitária Ruth Sandoval Marcondes, em entrevista concedida a Lina Faria, é bastante esclarecedor. (Veja-se Faria, 2006, p. 197-200).

7 Devemos esta observação a um dos Pareceres sobre uma versão anterior de nosso trabalho.
} 
lo, insistimos, o que se passava nos centros de saúde e nas visitas domiciliares era absolutamente significativo, ao favorecer, na relação entre os sexos, a consolidação de um espaço de ação e controle femininos.

Estamos, pois, já num outro recorte do campo da saúde, em que se defrontam as ocupações femininas, de modo geral, diante do poder médico e masculino. Focalizemos mais de perto o campo da Enfermagem. Apesar da subordinação de gênero, foi no campo emergente das profissões que a mulher pôde afirmar-se fora do circuito maternal, familiar ou doméstico. As primeiras lideranças da Enfermagem Moderna, particularmente na Europa, souberam captar tais dilemas (Castro Santos, 2008). Ainda que fossem conhecidas pelas profissões dominantes como "quase-profissionais" (Freidson, 1975), as discípulas de Florence Nightingale passaram a ocupar um novo campo de autoafirmação feminino. Houve resistências que a história registrou: por exemplo, na França, os enfermeiros rejeitaram a atuação da mulher nos hospitais, pois representavam uma ameaça a um território de predomínio masculino (Schultheiss, 2001, p. 126; Paicheler, 1995, p. 5-10; Faria, 2006, p. 178).

As lutas e negociações que se desdobram, em nossos dias, em vários países, revelam problemas entre as profissões e no interior da própria profissão. No Brasil, a esses problemas somam-se dilemas típicos do corporativismo particularista, tais como a tentativa atual de grupos médicos de garantir territórios “cartoriais" e limitar o exercício de atribuições comuns ${ }^{8}$, bem como o autoritarismo sindical dos Conselhos "classistas" em inúmeras atividades, a exemplo da Enfermagem. É importante contrastar tais dilemas, tipicamente particularistas, com as lutas profissionais de caráter mais universalista, que ocorreram especialmente nos Estados Unidos no início do século $X X$. Ali, diferentemente da Inglaterra, as enfermeiras de saúde pública cedo se afirmaram como movimento coletivo, criaram sua própria associação profissional - a Organização Nacional de Enfermagem de Saúde Pública, em 1912 -, foram recrutadas em bases mais democráticas do que suas colegas inglesas (BuhlerWilkerson, 1983; Davies, 1983), ou mesmo suas colegas brasileiras, nos primeiros anos da Anna Nery (Castro Santos e Faria, 2005).

Cabe aqui uma palavra sobre a comparação da realidade latino-americana e brasileira, em particular, com a européia ou norte-americana. 0 fato de serem sociedades com percursos históricos (culturais, econômico-sociais etc.) bastante diversos não invalida comparações; ao contrário, convida o observador atento a fazê-las e escapar da auto-referência, quase sempre teoricamente paralisante ${ }^{9}$. Na análise da formação das profissões de saúde, a singularidade de cada país pode ser preservada, desde que da estratégia comparativa se retirem questões ou perguntas que permitam não apenas a "abertura de foco" para outros países, mas o retorno ao foco inicial, que é a própria história singular de um dado país. Por exemplo, o trabalho recente de Ava Takahashi, sobre a profissionalização da Enfermagem japonesa na primeira metade do século XX, é uma referência necessária para que os estudiosos brasileiros possam aquilatar a subordinação e a subalternidade em países latino-americanos. Ainda que constituam traços marcantes entre nós, pesaram menos sobre as primeiras gerações de Enfermeiras do que no Japão, onde o militarismo, o nacionalismo e a xenofobia somaram-se ao forte componente patriarcal (Takahashi, 2002). A partir do "jogo de espelhos" da história comparada, o observador poderá deduzir a singularidade da experiência latino-americana em face da experiência internacional, ao mesmo tempo em que poderá captar as semelhanças de formação histórica, como a experiência patriarcal. Do mesmo modo, autoras como Ava Takahashi, sensível à existência de interesses políticos e econômicos das nações hegemônicas do hemisfério ocidental, ao fazer uso da análise comparativa, passa a distinguir duas lógicas distintas de operação, cujas possíveis interações ou intersecções são detectadas pela análise histórica concreta. Na experiência histórica nipônica, dirá a autora (Takahashi, 2002), a lógica da dominação imperial das na-

8 Devemos estas indicações a dois pareceres extremamente cuidadosos, sobre outra versão deste texto.

9 Para o leitor interessado, há uma copiosa literatura sobre os recursos da análise comparativa entre países, que aborda não apenas suas limitações e percalços, mas, principalmente, os benefícios do "jogo de espelhos" a que se obriga o observador, escapando da excessiva auto-referência metodológica e interpretativa. Um texto clássico da literatura latino-americana, a esse respeito, é a obra dos historiadores Ciro Flamarion Cardoso e Héctor Pérez Brignoli (Cardoso e Brignoli, 1979). Ava Takahashi (2oo2) expõe, de modo brilhante, a utilidade da historiografia comparada em seu estudo sobre a formação da Enfermagem no Japão. 
ções ocidentais se confrontará com um sistema político igualmente marcado pela tradição imperial e profundamente militarista. Nesse confronto, a lógica do profissionalismo será engolfada pelo espírito patriarcal-militar. Paradoxalmente, agências científicas de países capitalistas, como a Fundação Rockefeller, com seu modelo próprio de atenção à saúde pública, é que irão operar no Japão de modo a reduzir, ao longo do tempo, as resistências e dificuldades inerentes à difusão de uma ética e de uma práxis profissionais. No Brasil, a singularidade de nossa formação histórica - um conjunto de fatores, como a ausência de uma ideologia nacional-militarista - permitirá que a ideologia do profissionalismo em saúde pública se desenvolva, ao longo do período republicano, de modo distanciado dos interesses econômicos e políticos dos países centrais, como atesta a conduta das primeiras gerações de sanitaristas, enfermeiras e educadoras, formadas com o apoio da Fundação Rockefeller. ${ }^{10}$

Entre os fatores sublinhados para a difusão de uma ideologia do profissionalismo (um deles já mencionado), vários outros afetaram positivamente todos os países da América Latina, não apenas o Brasil. Tratava-se do início do processo de urbanização a partir das primeiras décadas do século XX, do aumento da ação estatal desde os tempos do Departamento Nacional de Saúde Pública, em 1920, da emergência de ideologias de modernização e de construção da nacionalidade e, não menos importante, do surgimento de grandes epidemias nos campos e nas cidades - como a febre amarela, a malária, a tuberculose e a ancilostomíase ${ }^{11}$. A partir do final dos anos de 1920, a educadora sanitária e a enfermeira de saúde pública tornam-se cada vez mais reconhecidas como atores importantes nos serviços de saúde pública. Firmavam-se diante das elites médicas, em especial pelo controle das práticas de educação sanitária nos centros e postos de saúde e nas visitas às famílias. Para tanto, as educadoras tiveram uma vantagem pelo manejo de "situações de ensino-aprendizagem", que os médicos não possuíam ${ }^{12}$, mas, indiscutivelmente, sem o êxito alcançado em suas atividades - para o qual concorreram diversos fatores, como o apoio do Serviço Sanitário e do então Instituto de Higiene, mais tarde Faculdade de Higiene e Saúde Pública da USP - de pouco valeriam os recursos pedagógicos. Sobre esse status legítimo diante da autoridade médica, uma pioneira das educadoras, Ruth Sandoval Marcondes, se exprimiu com orgulho, em depoimento recente (Faria, 2006) ${ }^{13}$.

\section{A Formação de uma Identidade Profissional}

A especificidade histórica da divisão do trabalho profissional em relação à divisão social do trabalho envolve, na concepção clássica de Durkheim, a acumulação do saber, o monopólio sobre uma esfera do trabalho e uma deontologia que, ao tempo que une os praticantes em torno de um conjunto de preceitos e condutas éticas, assegura-lhes condições de coesão associativa e controle ou avaliação da atuação de seus membros (Durkheim, 1977; Boudon e Bourricaud, 1993, p. 179184; 451-454). Esses fatores distinguem e hierarquizam as ocupações. Para o sociólogo Eliot Freidson (1975, 1998), a autonomia gera prestígio, status e poder às ocupações. Freidson, um notável estudioso das profissões, entretanto, desconsiderou os próprios estudos de sociologia da Enfermagem nos Estados Unidos e Canadá, que têm destacado o papel cada vez mais expressivo de enfermeiras e enfermeiros junto à opinião pública, a partir do surgimento da Aids (Fox e col., 1991). Mas a superação da posição subalterna da

10 Para uma discussão das relações de aproximação/disjunção entre os interesses políticos e econômicos das nações hegemônicas e a lógica do profissionalismo na saúde, no Brasil, ver Castro Santos e Faria (2005).

11 Existe ampla bibliografia sobre esse tema, em particular em relação à América Latina e ao Brasil.. Um texto representativo da bibliografia latino-americana é Hochman e Armus, 2004.

12 Agradecemos, nesta passagem, os comentários feitos por um dos pareceres que recebemos.

13 Note-se que as primeiras enfermeiras tinham de ter o curso ginasial, mas não eram, necessariamente, normalistas ou professoras primárias. A Enfermeira Clarice Ferrarini relata, a propósito, que, ainda muito moça, decidiu não ingressar numa Escola Normal, preferindo matricular-se na Escola Anna Nery e enfrentar "as dificuldades e o conceito não muito bom que era atribuído às enfermeiras" (Sanna, 2003, p. 1058-1059). Essa noção de classificação social “não muito boa”, devemos enfatizar, indica que a particularidade que as visitadoras desfrutaram ou adquiriram em relação aos praticantes da medicina - a competência para "ensinar” - não era suficiente para se firmarem o prestígio diante daqueles profissionais. Como indica Ruth Sandoval (depoimento citado em Faria, 2006), o status legítimo não foi algo atribuído sem dificuldades às visitadoras, mas conquistado na própria prática, durante a profissionalização em saúde. 
Enfermagem na verdade não vem de hoje, pois antecede a trágica eclosão da Aids. Por certo, refere-se a um elenco de conquistas palpáveis: a autoridade crescente diante das demais profissões, o poder social na esfera pública, a influência e o respeito junto ao conjunto de sujeitos - tidos como "usuários" - da atenção à saúde. Quando empregamos, no título do presente trabalho, o termo supostamente para qualificar a subalternidade, nos propúnhamos a enfatizar que, desde os primeiros tempos da Primeira República, apesar de a medicina hospitalar ditar as regras e os rituais de consagração dos cursos pioneiros de Enfermagem fosse no Hospital Samaritano, em São Paulo, fosse na Escola Profissional de Enfermeiros e Enfermeiras, na capital do País $-{ }^{14}$ a década de 1920 foi um período instaurador de espaços importantes de auto-organização, como a criação da Associação Brasileira de Enfermagem, a formação acadêmica em centros de excelência no exterior, o contato das lideranças nacionais com o movimento internacional, cujo eixo gravitava em torno do International Council of Nurses ${ }^{15}$.

Eliot Freidson (1975) define os parâmetros canônicos sobre os processos de conquista de um espaço autônomo pelas ocupações de saúde, que incluem, fundamentalmente, a demarcação de um território de escolhas e decisões independentes, isto é, a "organização social" em torno de uma tarefa. No entanto, lembra o autor, esse domínio ou controle de um campo de atuação é dificilmente atingido (p. 69). Ora, o que está em jogo é a própria noção de autonomia. Haveria outras possibilidades de conceituação de "autonomia"? Há autores que sugerem o conceito de "auto-organização", com um significado mais aberto ou polivalente. A capacidade de "auto-organização", segundo o sociólogo Edgar Morin (Morin, 1984), refere-se não tanto à capacidade de auto-gerência, mas resulta de processos complexos e recorrentes, que envolvem ordem perfeita e desordem, integração e isolamento, ou ain- da, acrescentaríamos, um jogo cambiante entre estados supostamente "puros" de dependência e independência funcional e social. A autonomia freidsoniana, nesse caso, teria de ceder espaço a concepções menos rígidas, pois a inflexibilidade conceitual passa a gerar noções de caráter normativo: para Freidson, mesmo uma ocupação plenamente institucionalizada, como a Enfermagem, subordina-se quanto a poder, status e prestígio, à medicina. Quando se atém a um único aspecto histórico das profissões, que é a tradição, o autor lhe confere peso excessivo: já que a medicalização tem penetrado profundamente no ambiente hospitalar, nos últimos duzentos anos, a supervisão dos médicos teria inibido as condições para o desenvolvimento de poderes paralelos (Freidson, 1975, p. 63-66).

Entretanto, os argumentos levantados por Freidson não respondem às novas questões trazidas pela dramaturgia da Aids. No próprio hospital, a disseminação dos cuidados paliativos a pacientes crônicos e terminais acentua as condições de atuação independente das equipes de Enfermagem (Fox e col., 1991). Freidson não chega a considerar essas situações, de nenhum modo excepcionais, na organização dos cuidados hospitalares, do ponto de vista dos graus de autonomia alcançados pela Enfermagem. Por outro lado, falta à visão freidsoniana, apesar de sua contribuição inegavelmente importante, o ponto de vista histórico. (Voltaremos a esse ponto mais adiante). Mesmo o território do hospital, cidadela típica do poder médico, já revelava concessões importantes para a Enfermagem há várias décadas, particularmente em países do Terceiro Mundo. O que se passava no Hospital das Clínicas de São Paulo, segundo o relato da Enfermeira Clarice Ferrarini, é exemplar: num movimento tipicamente dialético, a posição de subordinação hierárquica diante dos médicos estimulou uma líder do porte de Ferrarini a traçar um esquema de atribui-

\footnotetext{
14 Mott (1999) e Moreira e Oguisso (2005: cap. 6) dedicam atenção especial a este ponto.

15 Para uma crítica à noção de subalternidade do trabalho da Enfermagem, consultar Lunardi Filho, 20oo. Em trabalho posterior, Lunardi Filho e colegas sugerem, no entanto, que na organização do "fazer" das categorias da Enfermagem, "o que se observa, de modo preponderante, são profissionais que se têm submetido e submetem-se às determinações superiores", "em detrimento de sua própria autonomia" (Lunardi Filho e col., 2001, p. 95). Esse nos parece ser um processo dramático, decorrente, sobretudo, dos rumos de excessiva hierarquização do trabalho na Enfermagem, que produz e reproduz "subalternos", como os técnicos em Enfermagem ou "auxiliares de Enfermería”, em toda a América Latina. A OPAS tem focalizado o problema e soluções possíveis, pelo caminho da própria profissionalização dessa categoria (Malvárez e Heredia, 2005). A nosso ver, a superação de tais dilemas exige uma estratégia de análise comparativa das situações concretas ou graus de autonomia/subalternidade, em diferentes países da América Latina. 0 trabalho citado, patrocinado pela OPAS, constitui notável esforço nessa direção.
} 
ções e responsabilidades que criava, em última análise, um espaço de debates e de auto-organização para a própria Enfermagem. Naquele hospital de ponta na América Latina, o “poder” médico atuava, de fato, nas bordas da organização ou do sistema de atividades proposto pelo corpo de Enfermeiras (Sanna, 2003).

Questões particularmente sensíveis se colocam no caso da enfermagem de saúde pública. A nosso ver, essa atividade confronta a abordagem freidsoniana com perguntas fortes, pois é ali que a Enfermagem tem conquistado inegável capacidade de auto-organização, desde os tempos das visitadoras. Ieda de Alencar Barreira esclarece, em trabalho pioneiro, o modo pelo qual a "consulta de enfermagem" desprendeu-se da interferência médica (Barreira, 1975, p. 76-94), entre as várias situações de conduta autônoma que, em tempos recentes, a Saúde da Família veio consolidar. A enfermagem de saúde pública ocupa espaços importantes, não somente como parte destacada das equipes multiprofissionais, mas pela supervisão do Programa de Agentes Comunitários da Saúde. Trata-se de uma capacidade de liderança e atuação pública que parece retomar a notável experiência e o espaço simbólico, conquistados pela Enfermagem durante a Campanha Nacional contra a Tuberculose. Desde meados da década de 1940 e por trinta longos anos, esta experiência marcou, segundo Ieda de Alencar Barreira, "uma das raízes da Enfermagem brasileira" (Barreira, 1992, p. VI). Na verdade, é difícil entendermos as conquistas recentes sem as trilhas abertas pela "aventura da Campanha”, do mesmo modo como dificilmente se entenderá a força do movimento contra a tuberculose - seu "apelo dramático", no dizer de Ieda Barreira (p. 11) - sem evocarmos as lutas das enfermeiras nos primórdios da profissionalização, a consagração das Enfermeiras “Ananéri”, a experiência inovadora, no campo da atenção à saúde pública, das educadoras e enfermeiras visitadoras de São Paulo.

Se o trabalho de visitação às famílias foi um marco, a conformação de uma organização social da prática do cuidar foi uma condição necessária. Referimonos aos postos e centros de saúde que têm sido, desde 1925, no Brasil, um lócus de trabalho multiprofissional e, particularmente, de educação sanitária. A expansão dos aparelhos de Estado e os movimentos pela reforma da saúde, desde as primeiras décadas do século XX, sinalizavam um processo que não era apenas brasileiro, mas que reproduzia, com maior ou menor nitidez, o panorama latino-americano (Hochman e Armus, 2004). No Brasil, a transformação da saúde pública em "questão nacional" foi notadamente favorável para o surgimento de novas profissões da saúde, com seus conflitos de interesse, suas alianças estratégicas, suas formas de inserção no espaço público, difundindo-se do gérmen inicial de São Paulo e Rio de Janeiro para várias regiões do país e integrando a mulher - não sem grandes arestas e duras contradições - ao universo masculino.

Dificilmente se poderá sustentar que tais avanços na integração da mulher ao mundo do trabalho em saúde deixaram de ser pautados por novas estratégias de controle. Mas procuremos nessas estratégias seu avesso. O homem que diz "Eu controlo", nem sempre tem sucesso, e controlador e "controlada" freqüentemente têm papéis carregados de ambigüidade. Isso se deveu, em boa parte, ao caráter aberto, polissêmico, da educação sanitária como elemento-chave do modelo higienista. Nesse sentido, a mulher educadora e enfermeira se consagrava como mestra do cuidar e imprescindível nas atividades da prevenção.

\section{O Sagrado e o Profano}

A sociologia francesa das profissões tem no estudo de Dubar e Tripier (1998) um de seus pontos altos, pela contribuição metodológica da sociologia histórica. A ênfase no método histórico, de fato, está ausente na perspectiva freidsoniana, discutida ao longo deste trabalho. Dubar e Tripier focalizam o tema da conversão para ingresso no circuito profissional, como aprendizagem técnica e moral. O protestantismo "radical", para os autores, dá a chave para situar a importância das teorias pedagógicas e de formação intelectual e profissional nos países anglo-saxões. Esses elementos se fundiram aos elementos de vocação religiosa, de origem católica, e se difundiram, em escala mundial, para conformar uma ideologia de profissionalismo no interior da Enfermagem. Já destacamos a importância do pensamento de Durkheim em relação aos padrões ético-normativos das associações profissionais. Não é outra a contribuição de Weber, que nos legou um guia metodológico e histórico para compreendermos a importância de religiosos e da autoridade racional-legal na formação das instituições profissio- 
nais da era moderna (Weber, [1904-1905] 2006). O que faltou a um dos maiores intérpretes da Sociologia das Profissões, Eliot Freidson, foi distinguir o Cuidar da Enfermagem e áreas afins como fenômeno histórico, buscando apreender suas dimensões ético-normativas, a capacidade de auto-organização, a vocação para a política, a profunda interação com as esferas da vida privada e pública nas sociedades modernas. Em outras palavras, faltou-lhe, mas não faltou à literatura brasileira e internacional sobre a Enfermagem, uma discussão das condições concretas, ao longo da história, que permitiram às atividades do Cuidar livrar-se da carga pesada da subalternidade, na hierarquia das atividades profissionais.

$\mathrm{Na}$ abertura do presente trabalho, aludimos às questões postas pela institucionalização da ciência aplicada, no tocante ao campo da Enfermagem brasileira. Saberes institucionalizados, como a promoção da saúde materno-infantil, privilegiada pelas autoridades sanitárias da Primeira República, ou o desenvolvimento da educação em saúde, efetuado em nossos dias pelas equipes de Saúde da Família, significam, necessariamente, regras formais, rituais simbólicos, atribuição de papéis e direitos, sanções e recompensas, além de expectativas mais ou menos estáveis sobre a criação de relações sociais de solidariedade e administração de conflitos. Nessa área aplicada do saber, a Enfermagem trouxe uma bagagem do que hoje chamaríamos de "técnicas de intervenção social", particularmente naqueles países, a exemplo do Brasil, onde se organizou em associações e se empenhou, desde os primórdios do século XX, em lutas por direitos civis e sociais. Nesse sentido, importa pouco se noções importantes do cuidado, quanto à redução dos níveis de mortalidade infantil, apóiam-se em conhecimentos da área biomédica ou das especialidades médicas. 0 que importa, do ponto de vista da institucionalização a que nos referimos, é o impacto do desenvolvimento de uma práxis do cuidar que é, fundamentalmente, uma contribuição da Enfermagem. A partir dessa inserção marcada pela experiência, novos saberes se desenvolveram e se desenvolvem continuamente, assegurando à profissão uma contribuição no campo cognitivo. Seja no terreno hospitalar, seja nas frentes da saúde pública, a Enfermagem tem ocupado, nos programas de gestão e coordenação, um espaço de debates e de auto-organização que resulta do domínio de saberes e práticas.
Este é um ponto fundamental de uma agenda de pesquisas futuras; isto é, cumpre-nos captar os elos que a Enfermagem estabeleceu, desde a Primeira República no Brasil, com os aparelhos de Estado, com agências de cooperação internacional em saúde e com atores nacionais pertencentes ao que hoje chamaríamos de "terceiro setor", além da estreita interação com segmentos das comunidades científica, intelectual e política. 0 diálogo com a história representa um desafio permanente, pois a compreensão dos modos de ser, das práticas e das estratégias do profissionalismo no campo da Enfermagem terá de municiar-se das fontes históricas riquíssimas que aguardam o pesquisador, para emitir interpretações e julgamentos alicerçados. Esse desafio alcança todos nós, e exige, de nossa parte, um esforço metodológico e interpretativo para prosseguir com cautela.

\section{Referências}

BARREIRA, I. A. Estudo exploratório sobre a consulta de enfermagem. Revista Brasileira de Enfermagem, Rio de Janeiro, n. 28, p. 76-94, 1975.

BARREIRA, I. A. A enfermeira-ananéri no país do futuro: a aventura da luta contra a tuberculose. 1992. Tese - Escola de Enfermagem Anna Nery da UFRJ, Rio de Janeiro, 1992.

BOUDON, R.; BOURRICAUD, F. Dicionário crítico de sociologia. São Paulo: Ática, 1993.

BRASIL. Ministério da Saúde. Programa Agentes Comunitários de Saúde (PACS). Brasília, DF, 2001.

BUHLER-WILKERSON, K. False dawn: the rise and decline of public health nursing in America, 19001930. In: LAGEMANN, E. C. Nursing history: new perspectives, new possibilities. New York: Teachers College, 1983. p. 89-106.

CARDOSO, C. F.; BRIGNOLI, H. P. Os métodos da história. Rio de Janeiro: Graal, 1979.

CASTRO SANTOS, L. A. A vez da mulher camponesa: movimento social, identidade e saúde no Maranhão. Revista Brasileira de Estudos de População, Campinas, v. 20, n. 1, p. 43-62, jan./jun. 2003.

CASTRO SANTOS, L. A. Nursing. In: PALGRAVE (Org.). Dictionary of transnational history, Palgrave. Londres, 2009. 
CASTRO SANTOS, L. A.; FARIA, L. A cooperação internacional e a enfermagem de saúde pública no Rio de Janeiro e São Paulo. Horizontes, São Paulo, v. 22, n. 2, p. 123-148, jul./dez. 2005. Disponível em: $<$ http:www.saofrancisco.edu.br/edusf/publicacoes/ RevistaHorizontes/News1236content6275.shtml.>. Acesso em: 15 fev. 2008.

DAVIES, C. Professionalizing strategies as time-and culture-bound: American and British nursing, Circa 1893. In: LAGEMANN, E. C. Nursing history: new perspectives, new possibilities. New York: Teachers College, 1983. p. 47-64.

DUBAR, C.; TRIPIER, P. La sociologie des professions. Paris: A. Colin, 1998.

DURKHEIM, E. A divisão do trabalho social. São Paulo: Martins Fontes, 1977.

DURKHEIM, E. As formas elementares da vida religiosa. São Paulo: Martins Fontes, 2003.

FARIA, L. Educadoras sanitárias e enfermeiras de saúde pública: identidades profissionais em construção. Cadernos Pagu, São Paulo, n. 27, p. 173212, jul./dez. 2006.

FARIA, L. Saúde e política: a Fundação Rockefeller e seus parceiros em São Paulo. Rio de Janeiro: Fiocruz, 2007.

FOX, R. C.; AIKEN, L. H.; MESSIKOMER, C. M. The culture of caring: Aids and the nursing profession. In: NELKIN, D.; WILLIS, P.; PARRIS, S. (eds.) $A$ disease of society: cultural and institutional responses to Aids. Cambridge: Cambridge University Press, 1991. p. 119-149.

FREIDSON, E. Profession of medicine: a study of the sociology of applied knowledge. New York: Dodd, Mead, 1975.

FREIDSON, E. Renascimento do profissionalismo. São Paulo: Ed. da Universidade de São Paulo, 1998.

HOCHMAN, G.; ARMUS, D. (Ed.). Cuidar, controlar, curar: ensaios históricos sobre saúde e doença na América Latina e Caribe. Rio de Janeiro: Fiocruz, 2004.

KAKEHASHI, T. Y. Revista Brasileira de Enfermageme a política de identidade profissional da enfermeira no Brasil - 1932 a 1941. 1999. Tese (Doutorado em Enfermagem) - Escola de Enfermagem, Universidade de São Paulo, São Paulo, 1999.
LUNARDI FILHO, W. L. O mito da subalternidade do trabalho da enfermagem à medicina. Pelotas: UFPel; Florianópolis: UFSC, 2000.

LUNARDI FILHO, W. D.; LUNARDI, V. L.; SPRICIGO, J. O trabalho da enfermagem e a produção da subjetividade de seus trabalhadores. Revista LatinoAmericana de Enfermagem, Ribeirão Preto v. 9, n. 2, p. 91-96, mar. 2001.

MALVÁREZ, S.; HEREDIA, A. M. Profesionalización de auxiliares de enfermería en América Latina.

Washington, DC: OPAS, 2005.

MOREIRA, A.; OGUISSO, T. A profissionalização da enfermagem brasileira. Rio de Janeiro: Guanabara Koogan, 2005.

MORIN, E. Sociologie. Paris: A. Fayard, 1984.

MOTT, M. L. Revendo a história da enfermagem em São Paulo: (189o-1920). Cadernos Pagu, Campinas, n. 15, p. 327-355, 1999.

PAICHELER, G. Présentation: les professions de soins: territoires et empiètements. Sciences Sociales et Santé, Paris, v. 13, n. 3, p. 5-10, 1995.

SANNA, M. C. Clarice Della Torre Ferrarini: o depoimento de uma pioneira da administração em enfermagem no Brasil. História, Ciências, SaúdeManguinhos, Rio de Janeiro, v. 10, n. 3, p. 1053-1070, set./dez. 2003.

SCHULTHEISS, K. Bodies and souls: politics and the professionalization of nursing in France, 1880-1922. Cambridge, MA: Harvard University Press, 2001.

TAKAHASHI, A. The western mode of nursing evangelized?: Nursing professionalism in twentieth century Japan. In: STANTON, J. Innovations in medicine and health: diffusion and resistance in the twentieth century. Florence, KY: Routledge, 2002. p. 91-108.

UNIVERSIDADE FEDERAL DE JUIZ DE FORA. NATES. Pólo de Capacitação. Estratégia de saúde da família: curso introdutório para equipes de saúde da família. Juiz de Fora, 2003.

WEBER, M. A ética protestante e o espírito do capitalismo. São Paulo: Martin Claret, 2006.

Recebido em: 28/03/2007

Reapresentado em: 08/10/2007

Aprovado em: 19/10/2007 